\section{Anti-darwinism in Japan}

SIR-L.B. Halstead's article on the socalled Imanishi phenomenon, the popularity of the writings of Kinji Imanishi, emeritus professor of Kyoto University, among intelligent laymen in Japan, attempts to relate the phenomenon to the character of Japanese society and its scientific community. Imanishi points out that the competition and selection in Darwin's view of nature derive from the cultural and religious ethos of Western paternalistic society, whereas the Japanese view is maternal, one that sees the inherently harmonious nature of the living world.

After holding a visiting professorship at the department of geology and mineralogy of Kyoto University, Halstead explained the Imanishi phenomenon by pointing out that the present world, Japan in particular, is demonstrably a world of competition, struggle and disharmony. In such a world or society. Halstead writes, "Imanishi's theory can satisfy the dreams and aspirations of people in a desperate rat-race, serving as a dream-scape sentimentality. Unhappily it has no place in scientific understanding of the real world."

Halstead's observation is rational, axiomatic and persuasive. Yet it creates a certain disharmony in the minds of "average laymen" in Japan. It reminds us of Niels Bohr, who extended his complementarity principle in quantum mechanics to the realm of human concerns beyond natural science. He states that the rational scientific approach is only one way of dealing with the world around us. A given approach seems fragile and senseless when applied within the framework (cultural tradition) of another, but is forceful and convincing within its own frame?

One of the central concepts of Imanishi's evolution theory, the principle of life-style partitioning which later evolved into the idea of the harmonious nature of the living world, arose out of his early research on aquatic insect larvae, mayflies in particular, in freshwater streams. On the basis of recent researches in freshwater, marine and terrestrial habitats in experimental ecology which demonstrated that interspecific competition takes place in 90 per cent of all cases studied. Halstead claims that the statistical foundation of Imanishi's theory no longer stands. He adds: "this seems to have little effect on either the standing or on the public reception of Imanishi's ideas so long as he states he is not an ecologist. since then ecologists cease to discuss his theories. When Imanishi further states he is not a scientist, fellow scientists no longer feel there is any need to discuss his ideas." Thus Halstead concludes his article with the statement that vigorous debate and scientific confrontation are not part of the cultural tradition in Japan"... originality and innovation flourish in secret enclaves - Kyoto University saloon and coffee houses - beyond the experience of the ordinary Japanese, condemned, as they are, to the rigid authoritarian feudal society that masquerades as one of the advanced nations of the world."

My understanding is different. When Imanishi states he is not an ecologist, he is warning with A.N. Whitehead ${ }^{3}$ that the narrowness in the selection of evidence in science is the chief danger to the construction of a holistic world view. When Imanishi states he is not a scientist, he is proposing that the ultimate concern and responsibility of a scientist should be to free contemporary intelligent laymen from their cultural fragmentation by making them more conscious of the way in which art, morality, religion and science have become specialized, censorial, constrictive to the unbroken wholeness of our cultural experience.

As Halstead points out, the fundamental divide in man's view of the evolution of life has been the degree of emphasis placed either on observed variations among individuals or on the features held in common. Then the harmonious nature of the living world exemplified by the phenomenon of altruism and habitat segregation becomes susceptible to an explanation in terms of natural selection. It would then be a responsibility of a careful scientist to try to replace words such as competition and selection by more objective terms or words that do not change the essential scientific tenets of darwinism but greatly change their aesthetic, moral and religious connotations. Without a critical usage of the words, the notion of the survival of the fittest, for example, would become a tautology of the selection of the selected or the survival of survivors ${ }^{+}$.

It is encouraging that the progress of molecular genetics over recent years has developed new concepts such as evolution by gene multiplication and concerted or coincidented evolution" which are not inconsistent with Imanishi's ideal of the evolution of the harmonized holospecia in which all the individuals of a species evolve simultaneously when the time becomes ripe.

Needless to say, we are only beginning to understand the origin and the evolution of life. At present, we do not even know whether the evolution was gradual or sudden. As a rule, darwinian selection is more important over long periods of time and Motoo Kimura's picture of molecular evolution by random statistical fluctuation without selection (neutral theory) ${ }^{7}$ is more important over short periods. In reality the evolution must have been a complicated process with incidents of rapid change (punctuated equilibrium - de- velopment in bursts of evolution) ${ }^{\ltimes}$ separated by long periods of slow adaptation.

Finally, one of the persistent concerns of intelligent laymen in Japan since the time of the Meiji Restoration (1868) has been why science in the modern and current sense emerged in a restricted area of the world (Western Europe) and in a restricted period of time (early Middle Ages). It is commonly held that the synthesis of the Judeo-Christian conception of open-ended time and the Benedictine Order's motto "laborare est orare" lent progress and activism to the course of the history of Western civilization. We agree with Halstead that one of the secret enclaves of Kyoto University besides coffee houses, the Institute of the Humanities, where Imanishi's basic ideas and concepts took shape, was modelled after a medieval monastery in feudal Europe, though not of genuine Benedictine style.

NOBORU HOKKYO

Bioenergy Division,

Energy Research Laboratory,

1168 Moriyamacho, Hitachi,

Japan 316

1. Halstead, L. B. Nature 317, 587-589 (1985).

Weisskopf. V.F. Physics Today December 1985, 36-41.

Hall, D.L. in Buddhism and American Thinkers, (eds. Inada, K.K. \& Jacobson. N.P.), 14-15 (State University of New York Press. Albany, 1984)

Eigen. M. Naturwiss. 58, 465-523 (1971).

Ohno, S. Japan J. Hum. Genet. 26, $97-103$ (1982)

. Ohta, T. Genet. Res. Camb. 41, 47-53 (1983)

Kimura. M. Nature 217. 624-626 (1968).

Gould. S.T. \& Eldredge. N. Paleobiology 3. 115-119 (1977)

\section{Aussie disclaimer}

SIR-With reference to the News and Views article by Tony Thulborn entitled "Taxonomic Tangles from Australia" (Nature 321, 13; 1986), I wish to state that The Australian Journal of Herpetology and its Supplementary Series have no connection whatsoever with any of the Aus tralian Journals of Scientific Research (AJSR).

$A J S R$ is a series of 10 journals published by the Commonwealth Scientific and Industrial Research Organization in collaboration with the Australian Academy of Science. The biological science journals in this series are The Australian Journal of Botany and its Supplementary Series, The Australian Journal of Zoology and its Supplementary Series, The Australian Journal of Agricultural Research, The Australian Journal of Biological Sciences, The Australian Journal of Marine and Freshwater Research, The Australian Journal of Plant Physiology and Australian Wildlife Research.

Chairman, Board of the Australian Journals of Scientific Research) Australian Academy of Sciences,

GPO Box 783 ,

Canberra, ACT 2601,

Australia 